\title{
SOBRE A TRANSDISCIPLINARIDADE EM ATO NA PESQUISA CIENTÍFICA: ASPECTOS METODOLÓGICOS PARA DISCUSSÃO ACERCA DA INVESTIGAÇÃO SOBRE "CURSO DE VIDA E TRAJETÓRIA DELINQUENCIAL DE JOVENS E ADOLESCENTES"
}

ON THE TRANSDISCIPLINARITY IN ACT IN THE SCIENTIFIC RESEARCH: METHODOLOGICAL ASPECTS FOR THE DISCUSSION ABOUT "LIFE COURSE AND DELINQUENT TRAJECTORY OF YOUTH AND ADOLESCENTS"

SOBRE LA TRANSDISCIPLINARIEDAD EN ACTO EN LA INVESTIGACIÓN CIENTÍFICA: ASPECTOS METODOLÓGICOS PARA LA DISCUSIÓN SOBRE LA INVESTIGACIÓN SOBRE EL "CURSO DE VIDA Y TRAYECTORIA DELINCUENCIAL DE JÓVENES Y ADOLESCENTES"

\author{
Andréa Máris Campos Guerra* \\ Frederico Couto Marinho ${ }^{* *}$ \\ Ana Carolina Dias Silva ${ }^{* * *}$ \\ Ana Luiza Xavier Lelles ${ }^{* * *}$
}

\begin{abstract}
RESUMO
Apresentamos uma discussão epistemológica, ontológica e metodológica a respeito da transdisciplinaridade a partir de investigação sobre curso de vida e trajetória delinquencial de jovens e adolescentes no município de Belo Horizonte. Partimos de uma análise da estrutura de mudança e da relação de saber e poder entre as disciplinas envolvidas, tais que, psicanálise, sociologia e educação. Três aspectos relevantes foram levantados após breve construção teórica e apresentação da pesquisa: a transdisciplinaridade enquanto discussão teórica; a transdisciplinaridade em ato; a análise da implicação. A discussão conduzida no artigo leva à apresentação de três instrumentos metodológicos, construídos no percurso transdisciplinar que segue a pesquisa: narrativas memorialísticas, questionários e Planos Individuais de Atendimento (PIAs).
\end{abstract}

\footnotetext{
*Doutora em Psicologia pela Universidade Federal do Rio de Janeiro (UFRJ), com estudos aprofundados em Rennes II (França), professora Associada da Universidade Federal de Minas Gerais (UFMG), pesquisadora com Bolsa de Produtividade do CNPq e com pesquisa "Adolescências e Leis", financiada pela Fapemig, coordenadora do Núcleo de Pesquisa Psilacs (Psicanálise e Laço Social no Contemporâneo) da UFMG, psicanalista. E-mail: andreamcguerra@gmail.com.

"Doutor em Sociologia pela UFMG, com estágio de doutorado na Universidade Lille 1 (França), professor Adjunto do Departamento de Geografia da UFMG, professor no Programa Pós-Graduação em Promoção de Saúde e Prevenção da Violência, do Departamento de Medicina da UFMG, pesquisador do Centro de Estudos de Criminalidade e Segurança Pública (Crisp).E-mail: fcfrederico9@gmail.com.

"** Mestranda em Psicologia pela PUC Minas (Bolsista CAPES), psicóloga pela UFMG, com ênfase em Processos Clínicos e Formação Complementar Aberta em "Subjetividades políticas e Territórios”. E-mail: acdsilva.psi@gmail.com.

**** Graduanda em Psicologia no Centro Universitário de Belo Horizonte (UniBH), integrante do Núcleo de Pesquisas Psilacs (Psicanálise e Laço Social no Contemporâneo) da UFMG. E-mail: anaxlelles@gmail.com.
} 
Palavras-chave: Transdisciplinaridade. Aspectos metodológicos. Trajetórias.

\begin{abstract}
This text presents an epistemological, ontological and methodological discussion about transdisciplinarity from the investigation of life course theory and delinquent trajectory of young people and adolescents from the city of Belo Horizonte (Brazil). It starts from an analysis of the structure of changing and the knowledge and power relationship among the approached disciplines, namely, psychoanalysis, sociology and education. Three relevant aspects were raised after a brief theoretical construction and the presentation of a research: the transdisciplinarity as a theoretical discussion; the transdisciplinarity in act; the analysis of implication. The discussion held in this article leads to the presentation of three methodological tools, developed along the transdisciplinary route stridden by the research: the narrative of memoirs, questionnaires and the individual assistance plan (IAP).
\end{abstract}

Keywords: Transdisciplinarity. Methodological aspects. Trajectories.

\title{
RESUMEN
}

Presentamos una discusión epistemológica, ontológica y metodológica con respecto a la transdisciplinariedad a partir de investigación sobre curso de vida y trayectoria delincuencial de jóvenes y adolescentes en el municipio de Belo Horizonte (Brasil). Partimos de un análisis de la estructura de cambio y de la relación de saber y poder entre las disciplinas involucradas, tales como, psicoanálisis, sociología y educación. Tres aspectos relevantes fueron levantados tras breve construcción teórica y presentación de la investigación: la transdisciplinariedad como discusión teórica; la transdisciplinariedad en acto y el análisis de la implicación. La discusión conducida en el artículo lleva a la presentación de tres instrumentos metodológicos, construidos en el recorrido transdisciplinario que sigue la investigación: narrativas memorialísticas, cuestionarios y Planes Individuales de Atención (PIA).

Palabras clave: Transdisciplinariedad. Aspectos metodológicos. Trayectorias.

Por um lado, uma teoria é sempre local, relativa a um pequeno domínio e pode se aplicar a um outro domínio, mais ou menos afastado. A relação de aplicação nunca é de semelhança. Por outro lado, desde que uma teoria penetre em seu próprio domínio encontra obstáculos que tornam necessário que seja revezada por outro tipo de discurso (é este outro tipo que permite eventualmente passar a um domínio diferente). A prática é um conjunto de revezamentos de uma teoria a outra e a teoria um revezamento de uma prática a outra. Nenhuma teoria pode se desenvolver sem encontrar uma espécie de muro e é preciso a prática para atravessar o muro (Foucault, 1979). 


\section{INTRODUÇÃO}

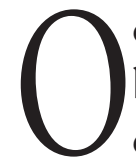
cenário urbano contemporâneo e suas mazelas, especialmente no contexto brasileiro, convidam e convocam atores para novas e inventivas reflexões e ações, em torno de problemas contingenciados. A desigual distribuição de riquezas aliada ao permanente estado de exceção (Agamben, 2004) no agenciamento político dos corpos somam-se ao acirramento do preconceito, à lógica do consumo e à individualização no laço social. Diante desse estado, a transdisciplinaridade, a solidariedade e as lógicas alternativas no nível da economia, majoritariamente, sinalizam possibilidades para o enfrentamento de problemas locais.

A complexidade se mostra como a marca de nosso tempo histórico e é necessário investigarmos mais detidamente os elementos que marcam os sujeitos, os coletivos, a cidade e seus modos de existência e de relação, a fim de operacionalizarmos ideias por meio de práticas efetivamente impactantes na realidade. O circuito dos afetos (Safatle, 2015) que sustenta a rede sociopolítica e econômica das populações em situação de vulnerabilidade evidencia a necessidade de se romper com a lógica das especialidades, a ser substituída pelo diálogo permanente "a partir" e "entre" os limites de cada campo disciplinar.

Nesse sentido, em um primeiro tempo de produção do grupo de pesquisas Curso de vida e trajetória delinquencial do Instituto de Estudos Avançados Transdisciplinares da Universidade Federal de Minas Gerais, tentou-se construir reflexões acerca do trabalho transdisciplinar. $\mathrm{O}$ objetivo era fundamentar os primeiros aspectos metodológicos do coletivo calcados na proposta do projeto como um todo, ou seja, subvertendo a maneira de produzir pesquisas científicas a partir da contribuição individual de cada membro coordenador (juntamente com as respectivas equipes) e sua trajetória de pesquisa com a infração. Assim, este capítulo apresenta uma reflexão sobre um novo modo de produzir ciência (pela construção transdisciplinar), tendo como foco o trabalho com jovens brasileiros em situação de vulnerabilidade social.

\section{SOBRE A LÓGICA DA TRANSFORMAÇÃO}

Os dois modelos actanciais básicos da lógica da transformação, propostos por Castro (2012) podem, nesse sentido, ser tomados como referência na escolha por modelos de agenciamento de mudanças. Ele propõe:

Rasgar a interface que separa o "lado de dentro" (o discurso antropológico [disciplinar]) e o "lado de fora" (o discurso do nativo [popular]) da relação de conhecimento e dobrá-la em 
uma fita de Möbius, mediante uma dupla torção idêntica àquela descrita por Lévi-Strauss na célebre fórmula canônica do mito (p. 158).

Figura 1 - Banda de Möbius

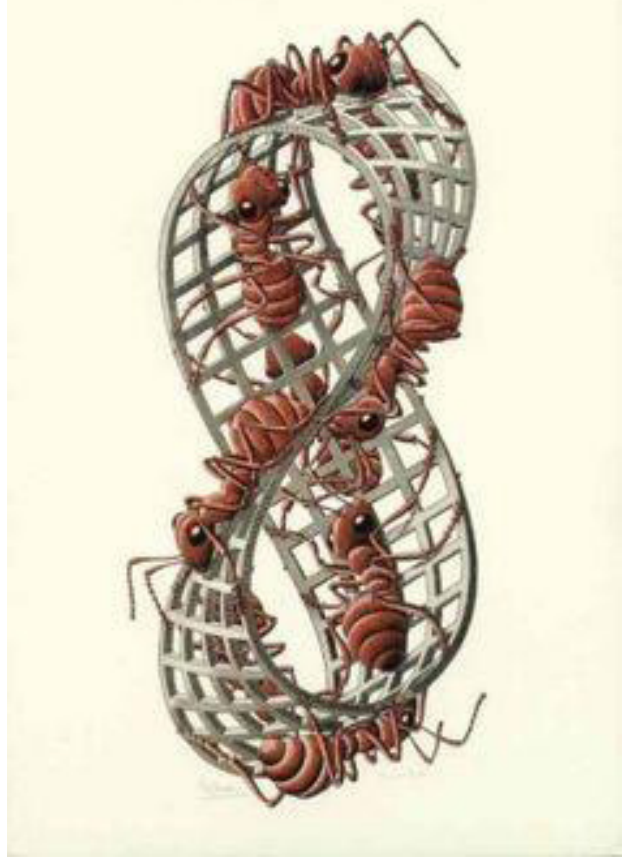

Fonte: Lacan (1962-1963)

No primeiro modelo, os coletivos-alvo são "objeto" e "paciente", mesmo que possam ser, contingencialmente, mediadores do processo. Trata-se de um modelo de "aculturação", no qual A diante de B o absorve e o incorpora como seu subtipo. Ele propõe chamá-lo de modelo "nominativo-acusativo" (Castro, 2012, p. 160). Seu funcionamento seria fazer o:

Coletivo-sujeito B passar de seu estado inicial (muitas vezes concebido como um estado primigênio) a um estado B', que contém dentro de si "partes" ativas de A (efeitos ou índices de A). O coletivo-ativo A normalmente termina por absorver o coletivo-passivo B como um estado a' de si mesmo (de A), isto é, como uma transformação duplamente "parcial" de A, uma variante empobrecida do coletivo-sujeito que é incluída como parte sua. [. . . ] No mais das vezes, essa concepção, para além de apenas descritiva, é crítico-normativa; ela lamenta a transformação de B, e se acompanha de um generoso desejo de emancipação de $\mathrm{B}$ em face de A. Sempre de acordo, porém, com as normas teóricas do discurso de A, entre as quais está a definição de A do que seja emancipação (Castro, 2012, p. 160).

$\mathrm{Na}$ segunda perspectiva, toma-se as partes como sujeitos. O esquema actancial da transformação é “algo como: B se transforma em B' por ocasião e intermédio da entrada de A em seu horizonte de eventos". Não se trata, portanto, apenas da mudança de estado, com a contenção de partes do coletivo. "No decorrer do 
processo, B-B' contratransforma A em A', na medida mesma de sua participação em A (que pode, aliás, ser muito pequena - ou não). Isso transforma o sistema formado por A, B e outras 'letras' em um superobjeto C” (Castro, 2012, p. 161).

Nessa perspectiva, a transformação não tem um vértice regulatório para o qual convergem as diferenças, não há finalidade especificada previamente nem valor supremo que separa, organiza e distribui o poder de maneira hierarquizada, por um lado. Ele torna obsoletas as noções de vítima, colonização ou liberação. E, por outro lado, não cai nem no hibridismo pós-modernista nem no romantismo da resistência. Estamos falando de uma outra modalização de relação com a alteridade, na qual a lógica da dominação é substituída pela da interação. Temos, como ponto de partida, uma visada da alteridade e de transformação em processo.

No sentido dessa segunda lógica actancial básica, discutiremos a seguir a dimensão metodológica da pesquisa transdisciplinar, com vistas a problematizar o método da pesquisa abaixo descrita.

\section{CONTEXTO DA PESQUISA SOBRE TRAJETÓRIAS E NARRATIVAS DE ADOLESCENTES EM CONFLITO COM A LEI EM SITUAÇÃO DE VULNERABILIDADE}

Com o objetivo geral de investigar, com base na transdisciplinaridade entre Sociologia, Psicanálise e Educação, o curso de vida de jovens acolhidos pelo sistema socioeducativo bem como identificar eventos que explicassem a entrada, permanência e, ou, não permanência, desistência e, ou, não desistência, específicos da experiência adolescente com a delinquência, foi constituído um grupo de pesquisadores dos campos da sociologia, psicanálise, educação e assistência social (Instituto de Estudos Avançados Transdisciplinares, 2017).

Após reuniōes sistemáticas de apresentação de perspectivas epistemológicas e conceituais de abordagem do adolescente autor de ato infracional em cada disciplina, deu-se início à tentativa de compor uma leitura em interface transdisciplinar do fenômeno da criminalidade na adolescência. $\mathrm{O}$ principal aspecto destacado nas discussões conceituais referiu-se à não consideração da perspectiva inconsciente e pulsional em modelos sociológicos racionais. Por outro lado, enquanto as séries de eventos recorrentes são identificadas pelas teorias sociológicas do curso de vida, a contingência e a singularidade que explicam sua incidência em apenas um grupo de jovens, a saber, os autores de ato infracional, exigia um olhar qualitativo e ecológico de seu contexto objetivo de vida e de suas experiências de subjetivação quanto à vivência desses eventos. Assim, não apenas a complexidade da leitura como também a construção de um saber sobre si e sobre sua história compartilhada, a ser elaborada pelo próprio 
jovem, mostravam-se necessárias.

Desta feita, associamos, em um modelo quanti-qualitativo, diferentes estratégias metodológicas, visando a dar conta da perspectiva transdisciplinar da investigação. Para esse fim, constituímos um estudo exploratório, de abordagem quantitativa e qualitativa, buscando qualificar melhor os eventos, transiçôes e rupturas que marcam as trajetórias dos jovens e adolescentes ao longo do seu ciclo de vida, desvelando seus nexos, movimentos e fatores condicionantes (IEAT, 2017).

Esta pesquisa partiu de informações obtidas de fonte documental oficial junto à Vara Infracional da Infância e Juventude de Minas Gerais, representada por processos judiciais de 300 jovens, que foram selecionados e tiveram sua trajetória analisada em perspectiva sociológica, a partir de pesquisa conduzida no ano de 2015. Assim, após três anos, essa amostra de jovens que caracterizou também a pesquisa do Instituto de Estudos Avançados Transdisciplinares (IEAT)/Universidade Federal de Minas Gerais (UFMG) encontrava-se dispersa territorialmente, podendo estar ou não em instituições prisionais ou socioeducativas, sendo difícil reuni-los em coletivos. Assim, era necessário pensar como construir uma metodologia transdisciplinar integrativa.

Nesta pesquisa atual, pensamos ser relevante considerar não apenas a subjetividade do jovem como também a rede de afetos, pessoas e objetos de seu contexto, bem como as instituições formais das quais participa, de maneira a impactar e modificar os condicionantes que o endereçam ao crime e à morte. A questão que norteia esse momento, assim, diz respeito a como compor efetivamente a abordagem do jovem e de seu contexto, de forma a que essa abordagem possa ter um caráter efetivamente transformador.

\section{REFLEXÕES PRELIMINARES TRANSDISCIPLINARIDADE COMO MÉTODO}

SOBRE

A

A fim de dialogar com os colegas colombianos (Gallo \& Ramirez, 2012; Cañas, Zuluaga, \& Gallo, 2008) e sul-africanos (Van Breda, Musango, \& Brent, 2016) acerca da ideia de transdisciplinaridade, retomaremos aqui algumas de suas premissas sobre essa lógica.

Em pesquisa premiada por maior impacto social na Colômbia, em 2007, um grupo de pesquisadores de Medellín se deteve na investigação acerca das dinâmicas de guerra e construção da paz, com base no estudo interdisciplinar da Comuna 13 daquela cidade. Esses pesquisadores, que tiveram um representante conosco no Brasil ao longo da pesquisa, ${ }^{5}$ buscaram a diferença entre as distintas 5 Um dos professores que conduziu tal pesquisa, Prof. Dr. Mário Elkin Ramírez esteve presente como catedrático do Instituto de 
epistemologias, mais que suas semelhanças, tendo sido seu ponto de convergência a formulação de uma pergunta comum: a conceitualização de violência, com base na experiência concreta da violência vivida na cidade de Medellín. Destacase seu caráter interinstitucional, envolvendo universidades e Organizaçôes não Governamentais (ONG).

O maior desafio e a maior riqueza do processo consistiram no modo de composição da diversidade de saberes e práticas que precisou ser ouvida como "outro", seguida desde o interior de cada lógica argumentativa, para que, daí, pudesse ser interpelada diante da pergunta norteadora da pesquisa. Esse trabalho exigiu muitas e prolongadas reuniōes bem como a consolidação de um modelo de processar e interpretar as informações obtidas. Com base em dimensões éticas, políticas, teóricas e filosóficas, chegou-se a acordos mínimos de orientação.

A dimensão subjetiva aliou-se à objetiva, num diálogo a partir da diferença, na qual se somaram saberes universitários, informais e comunitários na composição da leitura, tanto da lógica da violência na Comuna estudada quanto da análise dos fatores estruturais da violência. $\mathrm{O}$ estudo evidenciou as múltiplas formas de exercício da violência nesse território bem como os aspectos negativos de sua incidência na construção da paz e do restabelecimento de vínculos sociais no fortalecimento da sociedade civil. Buscou-se também inaugurar novas chaves de leitura do fenômeno da violência, a partir dessa composição transdisciplinar, bem como foram enviadas propostas estratégicas a autoridades governamentais com vistas a uma melhor adequação dos modelos psicossociais oficiais de intervenção e a realidade concreta e estrutural estudadas.

Van Breda, Musango, e Brent (2016), por seu turno, propõem expor alguns encaminhamentos a respeito da pesquisa transdisciplinar individual em três níveis de discussão e análise, a saber, ontológico, epistemológico e metodológico.

\subsection{Ontologia}

No polo da ontologia, os autores analisam, primeiramente, que o que se pode alcançar em termos da exploração da variedade dos objetos-fronteira (boundary objects), na pesquisa transdisciplinar individual, é muito amplo em relação a pesquisas estruturadas no âmbito macroinstitucionalizado. Em segundo lugar, surge a possibilidade de uma resposta integrativa e não separatista ou dicotômica em termos de sujeito/objeto, explorando-se seus diferentes ângulos. E, em terceiro lugar, "o que pode ser alcançado em esforços de pesquisa individual transdisciplinar pode não necessariamente ser resultados reais ou soluções produzidas no nível micro per se, mas sim os [próprios] processos individuais que Estudos Avançados Transdisciplinares (IEAT/UFMG) para participação do Projeto "Escola de Inverno: Metodologias e Práticas de Trabalhos Transdisciplinares", que ocorreu entre os dias 2 e 5 de julho de 2018. 
foram seguidos" (Van Breda, Musango, \& Brent, 2016, p. 155, tradução nossa)

O terceiro ponto ontológico apontado por Van Breda, Musango, e Brent (2016) mais especificamente parece se aproximar da proposta de Passos e Barros (2000) sobre o plano da clínica, visto que o que se pode extrair, por vezes, além da variedade e proposição integrativa, está relacionado aos processos individuais, o que pode ser traduzido nos termos da proposta da clínica política.

Em nossa investigação, nós nos perguntamos se, sendo a proposta de avançar do nível individual para o plano coletivo (entendendo, com a psicanálise, que, quando se está no plano subjetivo, há uma implicação do plano político social, necessariamente, como na lógica da banda de Moebius) então é preciso operar além do nível do diálogo com a ciência, ou seja, também no nível da pesquisaintervenção, num modelo que inclua o jovem, a família, a rede institucional e o território. Como fazê-lo?

\subsection{Epistemologia}

Para os autores (Van Breda, Musango, \& Brent, 2016), epistemologicamente, têm-se saberes coproduzidos, cogerados entre atores sociais e cientistas, com base em sistemas de saber integrativos e integrados. Os autores partem da ideia de que existem três tipos de conhecimento/saberes: conhecimento de sistemas, de alvos e de transformação. O primeiro "lida com a compreensão do contexto e de condições sociais sob as quais os problemas do objeto-fronteira estão sendo (re)produzidos, bem como realizando perguntas empíricas do que 'é' ou de fato 'constitui' a 'bagunça' ou 'insustentabilidade' desse último". O conhecimento de alvos, por sua vez, "lida com questôes normativas" da expectativa social. E por fim, o conhecimento da transformação "lida com questôes transitórias: perguntando quais processos e estratégias precisam ser perseguidos para mover $\mathrm{da}$ atual situação 'insustentável' para uma mais 'sustentável'” (Van Breda, Musango, \& Brent, 2016, p. 156, tradução nossa).

Os autores indicam que a decisão sobre qual dos três tipos de saberes uma pesquisa transdisciplinar individual cobrirá aponta a direção estratégica que ela seguirá bem como seu formato, indicando que não necessariamente os três pontos serão abarcados de maneira simultânea em uma pesquisa que propóe questionar o plano individual. Partir do mundo real para a produção teórica é uma questão epistemológica importante. A tradução de um problema social, do mundo real, em uma base teórica e em questôes de pesquisa, requer uma linguagem guiada pela produção desses conhecimentos/saberes (Van Breda, Musango, \& Brent, 2016). 
Nossa pesquisa lida com questões acerca do conhecimento de sistema e do de transformações, visto que a investigação do primeiro implica em descortinar as possibilidades do segundo. Perguntamo-nos, nesse momento, se devemos nos deter no conhecimento do sistema, de forma que, num segundo momento, ele possa subsidiar experimentações de transformação, também na forma de pesquisa acerca de desenhos metodológicos de intervenção.

A prioridade da produção do conhecimento parte do impasse do mundo social. Em nosso caso, trata-se do momento de produção a respeito do contexto e das condições de entrada, permanência ou desistência quanto ao crime, por adolescentes, e seu aspecto multifacetado, que está em jogo em nossa metodologia. No entanto esse trabalho nos indicou que devemos estar advertidos dos outros espaços, autores e conhecimentos que devem ser acionados com vistas à transformação, inclusive os próprios contextos de pesquisa. Daí a necessária transdisciplinaridade em ato no processo investigativo.

\subsection{Metodologia}

A "metodologia transdisciplinar refere-se ao raciocínio integrativo, lógica ou princípios para guiar o processo de pesquisa colaborativo de coprodução de conhecimento" (Van Breda, Musango, \& Brent, 2016, p. 157). Os autores ainda apontam que operar com princípios integrativos não se limita a trabalhar com as diferentes fronteiras das disciplinas, mas sim se trata de poder transitar entre os saberes e linguagens dos diferentes atores envolvidos no contexto da pesquisa.

Resultados socialmente úteis incluem, a propósito, novas políticas, estratégias, intervençōes, arranjos institucionais, planos de ação e conhecimento de transformação criticamente importante, os quais podem ajudar na transição para uma sociedade mais justa e sustentável (Van Breda, Musango, \& Brent, 2016, p. 161).

Van Breda, Musango, e Brent (2016) propõem então o desenvolvimento de uma discussão sobre "comunidades epistêmicas transdisciplinares", no sentido de uma articulação dos polos sociedade e ciência na formação e no funcionamento, e não apenas uma relação "entre" ou "através" desses mesmos polos. Trata-se de um "fenômeno muito mais 'híbrido' em que as 'comunidades epistêmicas transdisciplinares' podem ser construídas de processos individuais transdisciplinares" (p. 162). Nesse sentido, a reflexão de nosso grupo de pesquisas partiu da construção da metodologia de trabalho, com vistas a pensar a relação pesquisadores e sujeitos da pesquisa, mas também entre os próprios pesquisadores e os diferentes saberes envolvidos no ato da pesquisa. Durante todo o tempo de execução da pesquisa, desde a apresentação dos temas com foco nas disciplinas 
até a construção da metodologia em campo, o desenvolvimento da articulação entre sociedade e ciência se fez premente.

Van Breda, Musango e Brent (2016) também fortalecem o caráter de transformação que toma a vertente de intervenções na realidade concreta das populaçôes com as quais se propõe trabalhar, conjugada aos efeitos da implicação subjetiva que a pesquisa produz, a partir do diagnóstico que a metodologia transdisciplinar propõe realizar. Deacordo com os autores, a "Transdisciplinaridade (TD) emergiu nas últimas duas décadas não como uma 'nova' ciência per se, mas antes como uma resposta metodológica para a necessidade de um novo modo de fazer ciência com sociedade" (p. 151, tradução nossa). Ao apontar esses polos imbricados, sociedade e ciência, e o desenvolvimento transdisciplinar prático-teórico que apresente estratégias para enfrentar os complexos problemas sociais encontrados a partir dessa metodologia, os autores fazem uma ressalva importante: "A TD não é, assim sendo, um exercício puramente em raciocínio instrumental e prática, e não pode ser reduzido a uma ferramenta de solução de problemas ou método somente" (p. 151, tradução nossa). E concluem dizendo:

Isso significa que nós nunca podemos estar satisfeitos com meramente explicar (Erklarung) e compreender (Verstehen) a natureza complexa do mundo, sem também descobrir modos e meios de mudar (Verändern) o mundo, ou antes mudar nossas ações no mundo (Van Breda, Musango, \& Brent, 2016, p. 151, tradução nossa).

Essa construção cuidadosa é a aposta do grupo de pesquisas. Isso muda a relação social de desigualdade bem como as relaçôes de poder implicadas nos processos de criminalização da pobreza, de genocídio da população jovem e negra e do encarceramento da raça negra.

\section{ASPECTOS RELEVANTES PARA NOSSA DISCUSSÃO}

Consideramos, enfim, necessária a elucidação e pactuação em torno de alguns acordos mínimos (Cañas, Zuluaga, \& Gallo, 2008) quanto a três aspectos da pesquisa, de maneira que ela possa alcançar sua perspectiva sistêmica e transformadora (Van Breda, Musango, \& Brent, 2016). Eles seguem aqui reunidos para discussão.

\subsection{Transdisciplinaridade como interface entre disciplinas teóricas}

Como apontam Passos \& Barros (2000),

Problematizar os limites de cada disciplina é argui-la em seus pontos de congelamento e universalidade. Tratar-se-ia, nesta perspectiva transdisciplinar, de nomadizar as fronteiras, 
torná-las instáveis. Caotizar os campos, desestabilizando-os ao ponto de fazer deles planos de criação de outros objetos-sujeitos, é a aposta transdisciplinar (p. 77).

Assim, na interface entre disciplinas como a Sociologia, a Psicanálise, a Criminologia, a Filosofia política ou o Direito, emerge o desafio de acolher os sujeitos em sua singularidade, muitas vezes nomeados pelo pior, convidá-los ao deslocamento pulsional quanto ao seu modo de viver, e conectá-los com o Outro, num estilo de vida que suporta o "em comum", considerando a diferença de cada um. Para tanto, percebemos que promover o caos junto às teorias bemfundamentadas e estáveis de cada disciplina envolvida no grupo de pesquisas foi o ponto de partida na construção metodológica a que o coletivo se propôs. Assim o primeiro tempo de trabalho, na construção de estratégias para executar o estudo exploratório longitudinal, exigiu a reconstrução dos instrumentos de trabalho. Dessa forma, "criar uma continuidade através de uma dupla descontinuidade, fazer variar a verdade demonstrando a verdade da variação" (Castro, 2012, p. 158).

Dada a multiplicidade de singularidades com as quais lidamos, operamos com a "interface" entre diferentes domínios epistemológicos, compreendendo sua relação como "suplementar", ou seja, o que concerne especificamente a cada campo disciplinar torna-se suplemento do outro, no sentido de abrir uma nova condição de possibilidade analítica. Assim, configuram-se novos objetos. Dessa maneira, não concebemos, de saída, a relação entre os diferentes campos disciplinares como antagônica, hegemônica, excludente, necessária ou dialógica. Funcionamos tomando-os como campos "disjuntos", isolando elementos descritivos e analíticos para reflexão epistêmica e ação concreta (Guerra, 2015).

Por isso também concebemos como sociológica-clínico-política nossa metodologia. Com essa nova perspectiva, pudemos convergir o entendimento da cidadania e a subjetividade como superfície contínua não redutíveis entre si, mas sendo ambas capazes de produzir efeitos uma sobre a outra, na modulação dos modos de vida concernidos nos casos trabalhados sob sua ótica. Pretendemos, com ela, impactar população e jovem com perspectivas que deslocam preconceitos, e também informar sobre outros modos de viver, no compartilhamento de responsabilidades pela cidade e seus processos segregatórios.

\subsection{Transdisciplinaridade em ato}

Em nosso grupo de pesquisas, a aplicação de meios de transformação de realidades talvez deva ainda sedimentar-se mais. A sociedade está claramente implicada nos processos de pesquisa propostos, mas é preciso explorar a forma 
como os diagnósticos e a análise dos contextos podem levar a uma implicação concreta de todos os atores/autores na transformação da realidade das populaçôes com as quais lidamos. Importante sinalizar que o horizonte e uma parcela da potência transdisciplinar do trabalho encontram-se, principalmente, na iniciativa de um estudo pioneiro no Brasil, em sua metodologia longitudinal de análise contextual de jovens envolvidos em atos infracionais e, consequentemente, em situação de vulnerabilidade social. Carece pensar como os sujeitos-objetos podem refletir e trabalhar na mudança de sua condição em análise.

Em sua experiência aplicada a um contexto dos desafios da sustentabilidade, Van Breda, Musango, e Brent (2016) mostram que as pesquisas passam a utilizar uma lógica de objetos de estudo e seus contornos, fronteiras e limites (boundary objects), em detrimento a uma lógica de unidades de análise. Além de realizar um apelo ao binarismo (natureza versus social), a ideia de unidades de análise ainda desvia os propósitos transformadores, dando ênfase a análises apenas. Ao invocar a noção de contornos, automaticamente, as soluções precisam garantir praticidade, integração e inovação (Van Breda, Musango, \& Brent, 2016).

Diante desse risco dicotômico, colocamos sob análise nosso método, perguntando sobre o alcance e o efeito deste.

\subsection{Análise da implicação}

Passos e Barros (2000) propõem uma discussão sobre "a construção do plano da clínica e o conceito de transdisciplinaridade”, em que destacam, inicialmente, uma argumentação sobre a passagem do caráter da pesquisa-ação para a pesquisa-intervenção. A pesquisa intervenção surge então para criar uma nova relação entre o sujeito e objeto, mostrando que ambos se constroem no mesmo processo. Ressaltado pelos autores, vale lembrar que, na pesquisa-intervenção, são observadas as transformações como formas de diferenciação.

$\mathrm{Na}$ ascensão da concepção da pesquisa-intervenção, proporcionada por um processo que contou, "a partir dos anos 60, com a influência tanto da Psicanálise - que valorizava os aspectos inconscientes e a escuta analítica - quanto dos movimentos políticos - que criticavam o centralismo partidário" (Passos \& Barros, 2000, p. 72), e que desemboca no surgimento da análise institucional socioanalítica, ganha lugar a ideia da implicação dos atores envolvidos, que já estabelece, no momento da pesquisa, um caráter de intervenção, baseado "numa arguição que desmanchasse os territórios constituídos e convocasse à criação de outras instituições" (p. 73).

A implicação, por si mesma, gera um rearranjo de sentidos que evita a 
cristalização em discursividades e práticas sociais estigmatizantes, trazendo efeitos subjetivos e também sociais; motivo pelo qual pensamos sua inclusão propondo-a como novo elemento no desenho metodológico, como veremos melhor a seguir.

\section{ENCAMINHAMENTOS}

Nesse primeiro momento, portanto, pactuamos a partir de investigação acerca da transdisciplinaridade na pesquisa científica, algumas orientações para a efetiva construção metodológica desse estudo exploratório dos eventos e narrativas de jovens em situação de vulnerabilidade, especificamente, envolvidos com a infração.

Integrar teorias e métodos de diversas disciplinas das Ciências Humanas, Sociais e da Educação (objetivo do grupo de pesquisas aqui referenciado) é um dos maiores desafios teórico-metodológicos na área do desvio e do crime. A história dos estudos e pesquisas sobre a trajetória desviante/criminal é marcada por estudos situacionais. Há uma espécie de "refúgio no presente" que caracterizaria essas análises, como se a trajetória desviante/criminal investigada pudesse ser analisada de forma isolada no tempo e estática das demais trajetórias da vida social.

A integração transdisciplinar de teorias e métodos de diversos campos de pesquisa possibilita recuperar a dimensão processual, interacional e dinâmica das trajetórias (biográfica, familiar, comunitária, escolar, desviante, infracional e institucional) dos adolescentes por meio de um movimento dialético, qual seja, reconhecer a subjetividade da objetividade e a objetividade da subjetividade.

A integração transdisciplinar de teorias e métodos é um enorme desafio epistemológico que traz certa insegurança, pois não há modelos a serem seguidos, mas é compensada pela riqueza analítica que ela gera: é tanto uma realidade histórico-empírico (trajetória biográfica), uma realidade psicológica e semântica (o que o sujeito verbaliza e reflete retrospectivamente sobre o seu percurso biográfico) e uma realidade discursiva. Por possibilitar a reconstituição de parte de sua trajetória biográfica, a trajetória desviante/criminal pode ser analisada em relação à todas as trajetórias que a englobam.

Refletindo sobre essas possibilidades analíticas em um grupo heterogêneo de estudos e objetivando a construção de uma metodologia transdisciplinar, agregamos três instrumentos metodológicos à tarefa de pesquisa: as narrativas memorialísticas colhidas em encontros com entrevistas com os jovens, um questionário construído em sessões transdisciplinares de encontro entre os 
pesquisadores dos diferentes campos, e Planos Individuais de Atendimento (PIA) de adolescentes que passaram pelo Centro Integrado de Atendimento ao Adolescente Autor de Ato Infracional de Belo Horizonte (CIA/BH) no ano de 2015. Para contextualizar a produção que se deu com base na reflexão transdisciplinar que se produziu, introduzimos que:

a) as narrativas memorialísticas na pesquisa de fenômenos sociais (Guerra, Moreira, Oliveira, \& Lima, 2017) surgem como estratégia que permite apreender a ficção pela qual toda história é contada no sentido pulsional. Assim, faz-se possível, para o sujeito e para os pesquisadores, apreender os pontos nodais que enlaçam o sujeito na história e no próprio corpo, a partir de marcos na linguagem que tratam o impossível de significar como falta em torno da qual se abrem possibilidades subjetivas de criação e de elaboração, ou seja, de transformação;

b) as relações com a trajetória desviante/criminal podem ser analisadas pela produção de um tempo biográfico em questionários e entrevistas em profundidade, fora das instituições de cumprimento das medidas socioeducativas, acrescidas do saber do jovem sobre sua própria história não recolhida nem registrada nos relatórios dos sistemas judiciário e socioeducativo. Esses dispositivos permitem integrar teorias e métodos da Sociologia, da Psicanálise, da Educação e o saber do jovem, quando produzidos sob essa perspectiva transdisciplinar. Assim, produziu-se um instrumento de pesquisa que buscou conjugar aspectos levantados das análises provenientes das trajetórias de pesquisa anteriores, dos integrantes do grupo, em uma perspectiva ontológica, epistemológica e metodológica nova. Assim seria possível abrir possibilidades para tentar trabalhar os diferentes tipos de adaptação, negociação, conflitos e estratégias do ator social (adolescente) entre suas diferentes trajetórias (biográfica, familiar, comunitária, escolar, desviante, infracional e institucional);

c) o PIA é um instrumento formalizado pela Lei 12.594/2012, que institui o Sistema Nacional de Atendimento Socioeducativo (Sinase). O artigo 52 dispões que o PIA constitui um "instrumento de previsão, registro e gestão das atividades a serem desenvolvidas com o adolescente" no âmbito da execução das medidas socioeducativas (Lei 12.594/2012). Tal dispositivo também constituiu um instrumento de análise como fonte documental oficial, representada por processos judiciais. Isso possibilitou a prospecção da análise do horizonte institucional do curso de vida desses adolescentes.

A perspectiva transdisciplinar em que nos inscrevemos desenvolve a ideia de que o ciclo de vida dos adolescentes é o produto de um movimento 
multifacetado, da ação social dos sujeitos e dos constrangimentos estruturais, considerando as trajetórias tanto como efeito das estruturas longitudinais como o produto agregado que a ação social dos sujeitos inscreve na manutenção ou transformação dessas estruturas longitudinais. Assim estamos comprometidos com a ideia de que a abordagem do ciclo de vida e do conceito de trajetórias necessita ser trabalhada de maneira a subverter o modelo "nominativo-acusativo" indicado por Castro (2012), ou seja, na perspectiva de uma transformação.

É nesse quadro conceitual que se inscreve nossa pesquisa, dedicada à análise e compreensão das interações e efeitos da trajetória infracional sobre as diferentes trajetórias (biográfica, familiar, comunitária, escolar, institucional) dos adolescentes. Esta pesquisa está, portanto, na interseção entre diversas abordagens das Ciências Humanas, Sociais e da Educação. Os instrumentos metodológicos permitem a coleta e a análise de dados sobre a experiência cotidiana dos adolescentes, pensados de maneira a refletir um trabalho "trans": transformador e transdisciplinar. 


\section{REFERÊNCIAS}

Agamben, G. (2004). Estado de exceção. I. D. Poleti (Trad.). Belo Horizonte: Editora UFMG.

Cañas, P. E. A., Zuluaga, B. I. J., \& Gallo, H. (Orgs.). (2008). Dinámicas de guerra y construcción de paz: estudio interdiscplinario del conflito armado en la Comuna 13 de Medellín. Medellín: Universidade de Antioquia.

Castro, E. V. de (2012). "Transformação" na antropologia, transformação da "antropologia". Mana, 18(1), 151-171. Recuperado a partir de http://www. scielo.br/pdf/mana/v18n1/a06v18n1.pdf

Instituto de Estudos Avançados Transdisciplinares.(2017). Curso de vida e trajetória delinquencial: um estudo exploratório dos eventos e narrativas de jovens em situação de vulnerabilidade. Belo Horizonte: UFMG. Recuperado a partir de: https:/www.ufmg.br/ieat/2018/01/curso-de-vida-e-trajetoriadelinquencial/

Foucault, M. (1979). Microfísica do poder. R. Machado ( Trad. e Org.). (26a. ed.). Rio de Janeiro: Graal.

Gallo, H. \& Ramirez, M. E. (2012). El Psicoanálisis y la investigacion en la universidad. Buenos Aires: Grama.

Guerra, A. M. C. (2015). Um pouco sobre nossa estratégia de trabalho: psicanálise, marxismo e a vida pelo dentro e pelo avesso. In A. M. C. Guerra, C. de F. Cunha, M. da C. Aranha, M. B. e Souza, P. D. M. Penna, \& R. S. da Silva (Orgs.), Violência, território, familia e adolescência: contribuiçôes para a politica de assistência social. (pp. 17-42). Belo Horizonte: Scriptum.

Guerra, A. M. C., Moreira, J. de O., Oliveira, L. V. de, \& Lima, R. G. e (2017). The narrative memoir as a psychoanalytical strategy for the research of social phenomena. Psychology, 8, 1238-1253.

Lacan, J. (1962-1963). O seminário, livro 10: a angústia. V. Ribeiro (Trad.). Rio de Janeiro: Jorge Zahar, 2005. (Publicado originalmente em 1962-1963).

Lei 12.594, de 18 de janeiro de 2012. (2012, 18 janeiro). Institui o Sistema Nacional de Atendimento Socioeducativo (Sinase), regulamenta a execução das medidas socioeducativas destinadas a adolescente que pratique ato infracional; e altera as Leis n ${ }^{\circ}$ [. . . ]. Recuperado a partir de: http://www.planalto.gov.br/ ccivil_03/_Ato2011-2014/2012/Lei/L12594.htm 
Passos, E. \& Barros, R. B. de (2000). A construção do plano da clínica e o conceito de transdisciplinaridade. Psicologia: Teoria e Pesquisa, 16(1), 71-79.

Safatle, V. (2015). O circuito dos afetos: corpo politico, desamparo e o fim do individuo. São Paulo: Cosac Naify.

Van Breda, J., Musango, J., \& Brent, A. (2016). Undertaking individual transdisciplinary $\mathrm{PhD}$ research for sustainable development. International Journal of Sustainability in Higher Education, 17(2), 150-166. Recuperado a partir de http://dx.doi.org/10.1108/IJSHE-07-2014-0107 